\title{
The study of sports curriculum model optimization strategy in Medical colleges
}

\author{
Honglian GUO, Yue HUANG \\ Department of Physical Education \\ Hubei University of Medicine \\ Shiyan,442000,China
}

\author{
Eping YANG \\ Department of Physical Education \\ Hubei University of Medicine \\ Shiyan,442000,China
}

\begin{abstract}
By using literature, questionnaires and other methods are to discuss the theory and practice of physical education courses model optimization in medical colleges, after analysis it can point out that currently most physical education curriculum in medical colleges exist curriculum goals are not clear, medical characteristics are not prominent; course contents are obsolete, the phenomenon of setting course due to person is ubiquitous; teaching model is simplex and out of fashioned; the use of curriculum resources integration is not high, problems like it is difficult to ensure the study time and so on, in the meantime, combined the educational concept of lifelong sports and student-centered with the idea of training compound medical personnel under " Physical and Medicine combined ", put forward specific strategies to optimize physical education curriculum model in medical colleges: personnel training as a goal guidance, validate the objectives of sports curriculum; set reasonable sports teaching content, construct sports curriculum model under the idea of "Physical and Medicine combined"; make use of medical colleges' sports educational resources, the implementation of exercise teaching model; establish the concept of sporting classroom to create an open learning model of physical education curriculum.
\end{abstract}

Keywords- medical colleges; physical education curriculum model; optimization strategy; physical and medicine combined

\section{INTRODUCTION}

With the deepening of sports curriculum reform in general colleges, sports teaching model shows the trend of diversification. It is mainly to strengthen students' physical quality and to give full play to students' emotional experience, or to reflect students' three independent 'cluboriented sports teaching mode has gradually been tried and implemented in part of medical colleges, but in medical colleges, the dominant mode of physical education curriculum is still traditional physical education learning style based on technology. The organization of this physical class model mainly developed by three sections, that's to say the physical class is divided into the preparation section, the basic section and the ending section, each section has clear mission and target; teaching content around the "three bases", that is the basic knowledge, basic skills, and basic skills, demonstrated by teachers instruction and by students imitation, so that students can master the basic movement techniques, and reaches a certain level of motor skills.

\section{PROBLEMS ABOUT PHYSICAL EDUCATION} CURRICULUM IN MEDICAL COLLEGES AT THE PRESENT STAGE

A. curriculum goals are not clear, medical characteristics are not prominent

Since 2002 the Ministry of Education promulgated the "National Curriculum Physical Education in General Universities", various colleges have carried out physical education curriculum reform in varying degrees, and have achieved some effects, but due to the survey responses, most medical colleges haven't revised syllabus yet, physical education curriculum objectives are ambiguous, positioning is not clear, and they have no big differences in physical education curriculum compared with general colleges, medical characteristics are hard to reflect, only a very small part of medical institutions can try and make some adjustments according to the characteristics of the medical profession, sports curriculum and teaching content, such as Hainan medical colleges emphasize on penetrating exercise prescription principle, the effect of exercise physiology, knowledge about sports health benefits and so on in physical education, and add medical health education curriculum, focus on students unity of cognition about the correlativity between sports and medicine.

\section{B. $\quad$ teaching model is obsolete, phenomenon of setting course due to person is ubiquitous.}

At present, the physical education teaching contents are quite outdated in most of the medical colleges, lack of innovative teaching content, curriculum content is difficult to match the needs of the students, of which up to 60.73 percent of the school physical education curriculum content is obsolete, mainly in a traditional way, also easy to carry out such as ball games and athletics project-based, it's very common to open sports projects according to the teachers and the hardware facilities; only $23.27 \%$ of medical college's teaching contents are relatively new, in addition to offer traditional sports, they also opened fashioned sports programs which are favored by students, such as aerobics, dance, outward bound, skating, tennis and so on, take Liaoning medical colleges as an example, it has a variety of sports programs and rich content, not only stylish aerobics, skating and other sports, but also distinctive sepaktakraw, pearl balls and other sports. 


\section{C. outmoded teaching mode, simplex teaching method}

PE teaching mode is "teaching program embodied some kind of teaching ideas, which includes a relatively stable teaching process and the corresponding teaching methods system." [1]. Due to factors such as the traditional concepts and teaching conditions constraints, most of the current medical colleges face the same situation that their physical education teaching methods are tedious, basically did not get rid of the traditional teacher-led, restrained by the skillsbased teaching model. Relatively rigid organizational form of teaching, teaching method is relatively simplex, teaching is difficult to stimulate students' interest in learning, leading the situation that students like sports, but do not like physical education is ubiquitous.

\section{Course Resources utilization is not high, it is difficult to ensure the study time}

According to the feedback from the survey, currently in a considerable part of the single subject of medical institutions, physical education is only a "minor subjects", the integration of curriculum resources, hardware facilities and software development, and infrastructure construction have not attracted the attention of the relevant departments of the school yet, physical education curriculum hours are reduced, lack of teacher training, the construction of venues and facilities management backward, student learning conditions and sports time are hard to guaranteed. Currently, there are more than 90 percent of medical colleges opened physical education course for only two years, once a week, every semester teaching 16 to 18 weeks, except rainy days and exam delay, students' practical learning time, only 12 to 14 weeks each semester, 24 to 28 weeks a year, a total of less than 50 weeks in two years, which for five academic medical institutions, the two-year physical education for medical students is obviously very little [2].

\section{THE CONCEPT OF PHYSICAL EDUCATION CURRICULUM MODEL OPTIMIZATION IN MEDICAL COLLEGES}

\section{A. The concept of lifelong physical education}

Lifelong education as a modern educational philosophy is a necessary means of human continuous development and human self-realization. As an important part of life-long education, lifelong sports play an important role in improving the quality of human life and promoting human sustainable health development. And as the final stage of school physical education, college sports must adapt to the needs of social development on the basis of sustainable talent development, it will change the concept of lifelong education into the sustainable development of talent. Therefore, to optimize physical education curriculum model, the first thing is that we must follow the concept of lifelong physical education and let students to master the theory and methods of scientific training, to cultivate workout interest and awareness, to form the correct sports values and lay the foundation for lifelong physical activity through physical education activities during the school.

\section{B. Student-centered educational philosophy}

"To make the teaching truly turn into human culture, scientific development, and to achieve its function of educating people, it is essential to achieve students' principle position." [3], it reflects the concept of "student-centered" philosophy of education. "Student-oriented" is to ask the physical education curriculum to satisfy students' needs as the fundamental starting point, really concerned about students' physical and mental health. Pay attention to the dominant position of students during teaching, and focus on sports inspired and students' interest cultivated, through the creation of different teaching situations, inspire, and guide students to participate in sports classroom learning positively, to feel the entertainment of exercise, to cultivate students' exercise habits and lifelong sports consciousness.

\section{C. training compound medical personnel under "Physical and Medicine combined"}

Sport's goal is to enhance physical fitness, and promote health; medicine's goal is to prevent disease and to maintain heath. Sports and medicine are highly interlinked and fusion in maintaining human health, and in improving the physical constitution. As society's need for medical services, rehabilitation, health prevention and health education increased, sports and medical cross-integration will be more closely, the "Physical and Medicine combined " complex medical personnel who not only understands "doctor" but understands "body" will become an inevitable trend of sustainable development in modern society. Cultivate " Physical and Medicine combined " complex talent is the need of modern society, and it is the trend of medical education reform and development, it can not only promote the development of physical education and medical education, but also can promote the development of social sports and social medicine [2] . Therefore, college sports medicine curriculum reform must start with the idea of "Physical and Medicine combined " to train medical personnel, validate course objectives, the optimization of teaching content models have to serve the goals of personnel cultivation conducted .

\section{PHYSICAL EDUCATION CURRICULUM MODEL OPTIMIZATION STRATEGY IN MEDICAL COLLEGES}

\section{A. talents training target oriented, aim at validating sports curriculum in medical colleges}

According to the development trend of medical and sports, as well as the aim of cultivating complex medical personnel under " Physical and Medicine combined "philosophy, the target of sports courses in medical colleges should be audited for: cultivate moral, intellectual, physical, and aesthetic development, grasp the essential theoretical knowledge and motor skills about sports and health, master the necessary knowledge and skills about physical and medicine combined, medical and physical penetration, for medical, health services to be high-quality services combined 
talents that can work in health care and service organizations[4] .

\section{B. $\quad$ set reasonable sports teaching content, construct sports curriculum model under the idea of "Physical and Medicine combined"}

The specification of teaching content, the new teaching model will require more efficient teaching content. Therefore, medical colleges not only need to offer physical education class, but also need to give full play to the medical-related professional advantage, combined medical with sports to build " Physical and Medicine combined," [5]. As for the setting content, it should choose the way that can cultivate students then set up sports prescription, master sports hygiene, sports medicine and medical rehabilitation and other combined contents about "Physical and Medicine combined".

\section{C. make use of medical colleges' sports educational resources, implement exercise teaching model}

Physical education in medical colleges has unique advantage in medical teaching conditions, fully exploit and take advantage of this part of the resources, open courses such as physical health care, medical sports, sports medicine and other medical and physical combined, which related to students' career development, not only to improve medical students' ability to learn and to use medical, sports knowledge, the ability to service their own health, but also to further improve the competitiveness of the students future career. At the same time according to the resources of medical colleges physical education, implement exercise teaching model, so that students can learn through sports programs, they can not only master the skills of physical exercise and health care knowledge and methods about disease and rehabilitation, to better guide self -fitness, but also be able to use the knowledge and methods to practice, with the medical treatment of some diseases and health guide to patient with mild disease about rehabilitation, they can not only make diagnostic prescription, but also make exercise prescription, in order to serve the future career development better.

\section{D. establish the concept of sporting classroom to create an open learning model of physical education curriculum}

The development of students' physical fitness and health level, and the formation of sports behavior and habit, are all required persistent exercise time and intensity to gradually achieved, apparently only two hours of physical education a week is far from enough due to time and intensity. Establish sporting classroom concept is to organic combine school's physical education classes with outdoors to create its own open-physical learning environment and physical learning for students, not only school physical education time and space can get expanded, limited sports resources can be fully used, but also provide a certain time and space conditions as well as material conditions for the full play to the leading role of both students and teachers.

\section{CONCLUSIONS}

Teachers should focus on the cultivation of students' exercise interest and improve students' awareness of physical and medicine combined, pay attention to encourage students to do extracurricular self-training, and to their abilities to learn and teach from each other and selfevaluation. Furthermore schools should take advantage of weekends; holidays, etc. to organize students to attend health and hygiene awareness training lecture in school or community, to carry out the medical examination, fitness test, used the knowledge they learned to make exercise prescription for testers and guide testers' to do scientific fitness. This method can let students have a early contact with the society, not only to consolidate and improve the students" knowledge about "physical and medicine combined " and their ability to solve problems, but also to enhance students' social adaptability and competitiveness after graduation.

\section{ACKNOWLEDGEMENTS}

Fund:

Hubei Provincial Education Science "Twelfth Five Year Plan" 2012 research topic (2012B275)

\section{References}

[1] Mao Zhenming, Wu keys and other sports teaching model theory [J] Sports Science, 1998,18 (1): 5-8. Feasibility study

[2] Fu Lanying, Yang Xiaolin, such as "medical-binding" compound Training Mode [J] Beijing Sport University, 2011,34 (1): 96-99

[3] Liu Hrqun. Modern pedagogy new draft [M] Wuhan: Wuhan University Press, 2004: 152.

[4] Chen Yinglan. Body Integrative Medicine - development model of medical colleges sports teaching reform $[\mathrm{J}]$ Sports Culture Guide, 2006 (2): 66-67.

[5] Fu Lanying, Liu Jia independent medical colleges Compound Talent teaching model features [J] Henan Institute of Science and Technology, 2011 (9): 88-91 